Review

\title{
Satnav for cells: Destination membrane fusion
}

\author{
Matthew Holt* \\ Laboratory of Glia Biology, VIB-KU Leuven Center for Brain and Disease Research, Herestraat 49, B-3000 Leuven, Belgium
}

\section{A R T I C L E I N F O}

\section{Keywords:}

Membrane trafficking

Synaptic vesicle

Membrane fusion

SNARE proteins

Fusion specificity

Synaptic plasticity

\section{Why do cells need a satnav?}

Eukaryotic cells are elaborately subdivided into functionally distinct, membrane-enclosed compartments - or organelles. Each organelle contains its own characteristic set of enzymes and other specialized molecules, which allows for the segregation of distinct biochemical reactions. A complex distribution system transports specific products (or cargos) from one compartment to another, involving a cycle of trafficking vesicle formation from a precursor membrane, vesicle transport to its destination (which may involve use of the cytoskeleton and specific motor proteins) and finally vesicle fusion with its target membrane.

Such trafficking reactions underlie all aspects of eukaryotic cell function from protein synthesis and export (e.g. cell wall components in plants), autophagocytic turnover of used or damaged proteins (in, for example, budding yeast), through to cell-cell communication via the release of small molecule transmitter substances (such as found in the mammalian central nervous system: CNS). Given its central importance to cellular function, defects in the intracellular trafficking system have been linked to a whole range of diseases, from diabetes and cancer, through to neurodegenerative conditions [1]. Despite the wide range of specialist cells types found in eukaryotes, and the diversity of trafficking steps, the underlying machinery controlling membrane trafficking is remarkably conserved between reactions [2].

\section{Chemical neurotransmission in the nervous system: a model for vesicle trafficking}

Many of the guiding principles of membrane trafficking were originally worked out using the trafficking of synaptic vesicles and neurotransmitter secretion from neurons of the CNS as a model. Why was this system chosen? Simply put, CNS material (and synaptic vesicles) have been easily obtainable in large quantities for experimental use [3]. However, the general principles and machinery elucidated in this system have been found to be largely shared across membrane trafficking pathways employed from plants to mammals - operating in constitutive transport events (such as transferrin receptor recycling) [4], through to regulated secretion of chemical messengers from cells (such as neurotransmitter release from astrocytes [5], adrenaline release from chromaffin cells [6] and insulin secretion from pancreatic beta cells [7]). As such, in this review, we will use the molecular machinery underlying neurotransmitter release from neurons to illustrate defining principles of membrane trafficking.

Fast communication between neurons in the CNS occurs at specialist contact sites - synapses [8]. Small trafficking vesicles in the presynapse are filled with chemical messengers, such as glutamate or gammaamino-butyric acid (GABA). These vesicles are transported to specialist release sites on the plasma membrane - active zones. After docking to release sites, vesicles undergo a complex set of reactions that renders them fusion competent - priming. The arrival of an action potential in the presynaptic terminal leads to the opening of voltage-gated $\mathrm{Ca}^{2+}$ channels in the plasma membrane and a subsequent influx of $\mathrm{Ca}^{2+}$ leading to fusion of the vesicle with the plasma membrane and release of neurotransmitter. The precise mode of fusion is still debated, with two common models cited: transient opening of a fusion pore (so-called 'kiss-and-run'), or full merger of the vesicle with the plasma membrane. After fusion, vesicle membrane is recovered by endocytosis. Various forms of endocytosis, ranging from ultrafast recovery of vesicles

\footnotetext{
*Corresponding author at: Laboratory of Glia Biology, VIB - KU Leuven Center for Brain and Disease Research, KU Leuven Department of Neuroscience, Herestraat 49 , B - 3000 Leuven, Belgium.

E-mail address: Matthew.Holt@kuleuven.vib.be.
} 
A

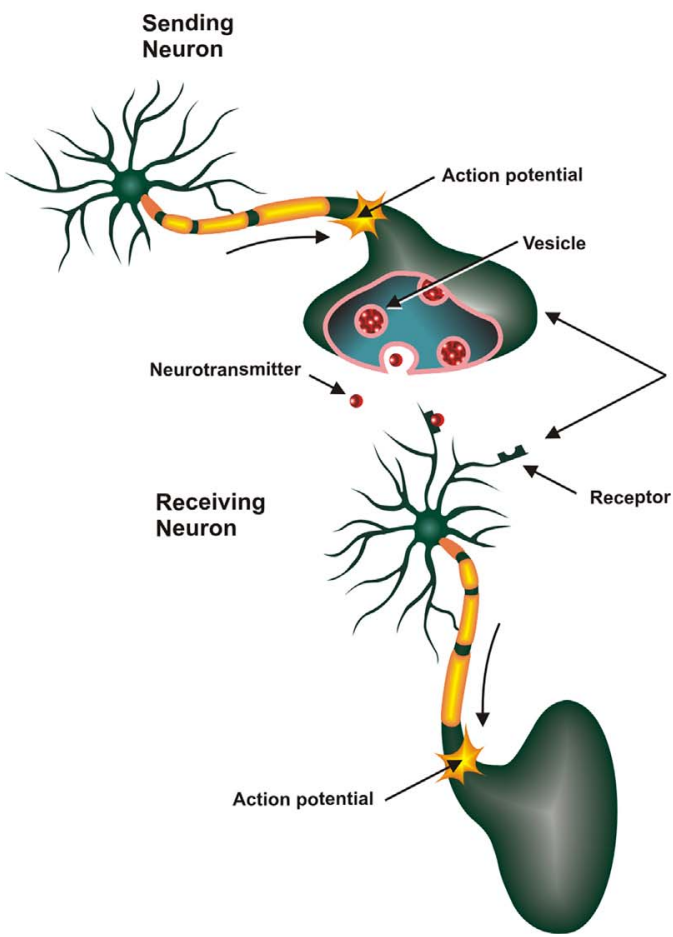

B

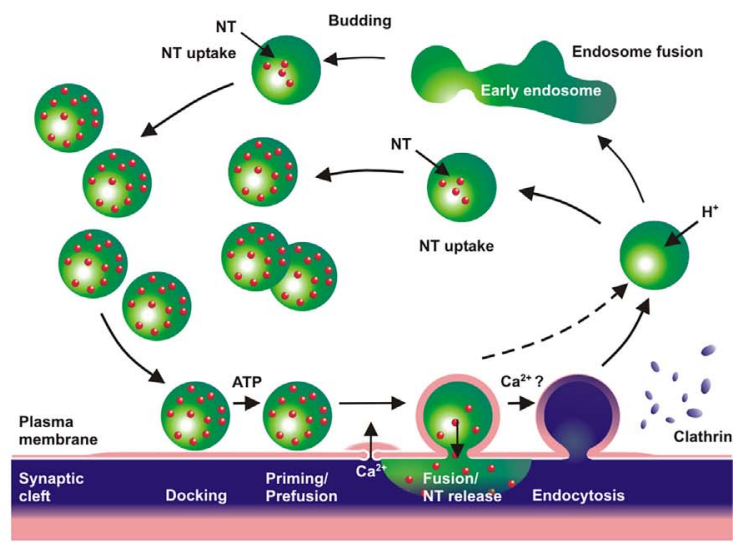

Fig. 1. Synaptic transmission and the synaptic vesicle cycle.

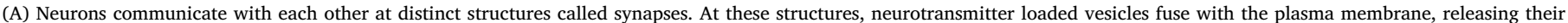

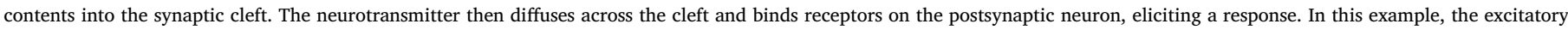

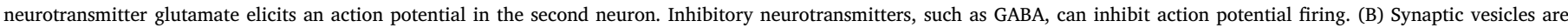

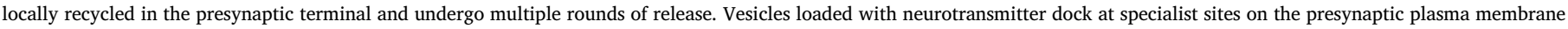

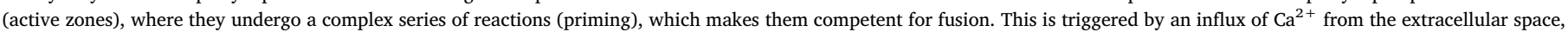

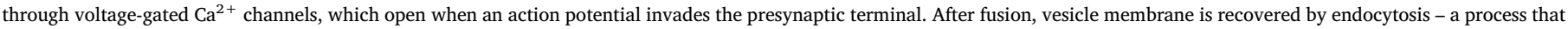

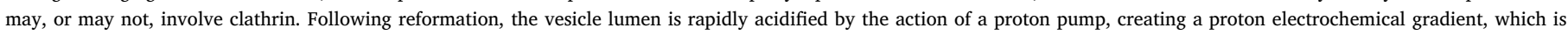

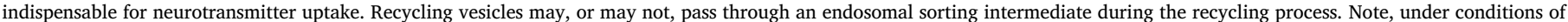

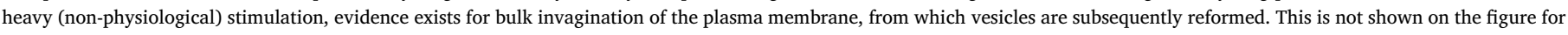
purposes of clarity.

through to slow recycling via clathrin-mediated mechanisms, have been put forward [9-11]. To a degree, the route of recovery likely depends on the mode of fusion (see above), stimulation paradigm and molecular composition of the vesicle (also see later) $[9,11]$. It is unclear whether endocytosis takes place at the active zone, or occurs at peripheral sites, although evidence for both exists. The vesicle lumen is then rapidly acidified by the action of a proton pump, driving the uptake of neurotransmitter into the vesicle. It still remains unclear whether recycling vesicles pass through an obligate sorting intermediate (early endosome) that acts as a proof-reading station, ensuring quality control, and/or removing damaged vesicle components and allowing their replacement (Fig. 1). A typical hippocampal synapse contains on average 200 vesicles, which can be recycled at least hundreds, if not thousands, of times [3]. The entire synaptic vesicle cycle can take up to $1 \mathrm{~min}$. Vesicle fusion with the plasma membrane occurs on a time-scale of milliseconds in response to $\mathrm{Ca}^{2+}$ influx in some ultra-fast synapses, endocytosis is completed with an approximate upper time limit of $5 \mathrm{~s}$, with the remaining $55 \mathrm{~s}$ being used for other steps in the cycle.

Obviously, the synaptic vesicle cycle is an extreme example of membrane trafficking: the long distance between the cell body and presynapse (over $1 \mathrm{~m}$ in cases such as spinal cord neurons), combined with the slow rate of axonal transport [12], is the reason behind a local recycling mechanism. This system imposes a series of constraints that serve to illustrate the precision that is achieved within membrane trafficking pathways. At any given stage of the recycling process, mechanisms must exist which encode the current 'status' of the vesicle. As the vesicle is the only constant at each stage of the process, this must be by (reversible) modification of integral membrane proteins, or by the transient recruitment of cytosolic factors to the vesicle [13]. Nowhere is the need for a precise and temporally resolved 'vesicle identity' greater than at points of membrane fusion - whether that is with the plasma membrane or with an early endosome. In this review, I will discuss the (general) molecular mechanisms behind membrane fusion. Furthermore, by comparing and contrasting aspects of membrane fusion at these two distinct points of the synaptic vesicle cycle, I will attempt to illustrate how specificity is achieved. Finally, I will briefly discuss whether dynamic alterations in the presynaptic release machinery can modulate synaptic output. By no means is it possible to give an exhaustive overview of the literature in a short piece: rather, I hope to use selected examples to illustrate much of our current thinking and the prevailing consensus view of membrane fusion.

\section{The membrane fusion machinery}

\subsection{Energy is everything}

Although to date it has proved impossible to capture the precise structural intermediates along the fusion pathway, in silico simulations and a growing amount of experiment data suggest a well-ordered process, in which fusion is initiated by a point like protrusion between two membranes, which results in formation of a hemifusion intermediate (in which the proximal leaflets of the membrane bilayers are fused). 
Expansion of the hemifusion intermediate then results in a fusion pore (at which point complete merger of the two lipid bilayers is achieved). In the case of neurotransmitter release, fusion may or may not proceed past the fusion pore stage, depending on whether 'kiss-and-run' or 'full collapse' modes of vesicle fusion are used (reviewed extensively in [14]). As phospholipid bilayers have a negative surface charge (because of the hydrophilic phosphate headgroup on lipids), this entire process is energetically very expensive. While there is good evidence that small synthetic liposomes (approx. $25 \mathrm{~nm}$ diameter) can undergo spontaneous fusion, due to their high curvature energy [15], biological membranes are highly complex with asymmetric lipid composition [16], high protein density [17] and a range of sizes. Sizes range from approx. 30-70 nm diameter for synaptic vesicles [17], and approx. 150-200 nm diameter for large dense core vesicles [18]. In comparison, the plasma membrane at the active zone is effectively flat [19].

\subsection{SNAREs as fusion engines}

Extensive experimental evidence (including sensitivity to botulinum toxins that inhibit exocytosis) places members of the Soluble $\underline{N} S$ Attachment REceptor (SNARE) superfamily of proteins as central players across membrane fusion reactions in eukaryotes. The three SNAREs classically associated with synaptic transmission (cognate SNAREs) are synaptobrevin 2/vesicle associated membrane protein 2 (VAMP2) on the synaptic vesicle, and syntaxin 1 and SNAP-25 on the plasma membrane [2]. Extensive in vitro analysis has allowed us to gain a detailed mechanistic understanding of how this fusion machinery works, which appears to be generally applicable across fusion reactions.

SNAREs differ in both size and structure; for instance, synaptobrevin and syntaxin are both held at their respective membranes by single Cterminal transmembrane regions (which are crucial for transducing force during the fusion reaction), whereas SNAP-25 is attached to the membrane via four palmitoylated cysteines [2]. In addition, syntaxin 1 is thought to have an extended N-terminal region, which modifies protein function through interactions with accessory proteins, such as Munc18 (see below). However, all SNAREs share one defining sequence - the SNARE motif. The SNARE motif is 60-70 amino acids in length and includes eight heptad repeats, that are indicative of coiled-coil motifs. Synaptobrevin and syntaxin both contain one SNARE motif, and SNAP-25 contains two (Fig. 2A). SNARE motifs are largely unstructured in solution. Interactions between the proteins initially start in trans: a transient $\mathrm{N}$-terminal interaction of SNAP-25 and syntaxin on the plasma membrane forms a binding site for the N-terminal region of synaptobrevin on the vesicle [20]. A tight bundle of four parallel $\alpha$-helices (the so-called core complex) is formed as the proteins 'zipper up' towards the C-terminal membrane anchors (in three distinct assembly stages) [21,22]. It is thought this process effectively drives fusion by forcing opposing membranes together (with zippering extending beyond the SNARE motifs and into the transmembrane regions) [2,22] (Fig. 2B).

After fusion, the SNARE complex resides in the plasma membrane in a highly stable, low energy cis configuration. Disassembly requires the action of the AAA ATPase $\underline{\mathbf{N}}$-ethylmaleimide-Sensitive Factor (NSF) and its cofactor alpha-Soluble NSF Attachment Protein ( $\alpha$-SNAP), with one SNARE complex disassembled per round of ATP turnover [23]. Synaptobrevin can then be recycled by endocytosis (see above) and syntaxin and SNAP-25 reset for use in further rounds of vesicle fusion. Note that NSF/ $\alpha$-SNAP activity also appears essential to prevent the production of unproductive 'dead-end' complexes on the plasma membrane, formed by the transient syntaxin-SNAP-25 acceptor complex (which is inherently unstable) recruiting a second syntaxin (instead of synaptobrevin) [24]. The regulation of SNARE complex formation and fusion is discussed below in greater detail.

'Zippering' with concomitant formation of (structurally conserved) core complexes is a universal hallmark of SNARE-mediated membrane fusion, including endosome fusion (which is mediated by a distinct set of SNAREs: syntaxin 13, syntaxin 6, vtila and VAMP4) [25]. From a biochemical perspective, once $\mathrm{N}$-terminal nucleation has initiated, SNARE complex zippering should proceed to completion, resulting in membrane fusion. However, neurotransmitter release at the synapse is distinguished by two key features - namely speed and a strict dependence on the level of intracellular $\mathrm{Ca}^{2+}$. This led to the suggestion that the process is regulated at a late step before full fusion, possibly involving the formation of partially zippered trans-SNARE complexes. In various models, complexin prevents partially assembled SNARE complexes from proceeding to a fully zippered state. The molecular basis of this 'fusion' clamp is still debated [26,27], but a popular concept is that the vesicular $\mathrm{Ca}^{2+}$ sensor, synaptotagmin, releases the clamp when it binds $\mathrm{Ca}^{2+}$, by (partially) displacing complexin from the SNARE complex. It is currently not clear if any other SNARE complex, such as the endosomal fusion apparatus, is subject to similar regulatory mechanisms.

\subsection{How many SNAREs are needed for membrane fusion?}

Remarkably, it has been extremely difficult to measure the energy needed to merge two membranes, with simulations placing the energy across a broad range of $40 \mathrm{kBT}-200 \mathrm{kBT}$ (depending on the assumptions made) $[28,29]$. Estimates of the number of SNARE complexes needed have been put at anywhere between 3 and 11 [30]. In truth, the minimal number likely depends on a number of factors, including the size (and curvature stress) of the vesicle [31], as well as the local lipid environment [32]. However, it is likely to be towards the lower end of this estimated range, as fusion between $60 \mathrm{~nm}$ diameter liposomes (composed of pure phosphatidylcholine) only required in the region of $30 \mathrm{kBT}$ [33]. Such a low energy threshold is well positioned to minimize spontaneous fusion in the presynaptic terminal, while enabling rapid SNARE-dependent fusion in response to $\mathrm{Ca}^{2+}$ influx, particularly when considering that SNARE proteins may act in concert with membrane deforming proteins (including synaptotagmin) to trigger fusion [34]. This would explain findings where two SNARE complexes are minimally sufficient for fast fusion of synaptic vesicles [35], and three SNARE complexes are sufficient for fusion of chromaffin granules [30]. This ambiguity regarding the minimal number of SNAREs needed for fusion raises two important questions. The first of these addresses the nature of the fusion pore during membrane merger, and whether it is purely lipidic or whether it is formed, at least in part, by transmembrane helices of the SNARE complex [36]. Interestingly, the stability of the fusion pore may actually be dynamically regulated by the number of SNARE complexes formed [37,38], possibly in combination with SNARE accessory proteins, such as the SM protein Munc18 [39] - with consequences for whether fusion occurs via a 'kiss-and-run' type mechanism or via full fusion (see above and Fig. 1). Second, it is also unclear why SNAREs are expressed at extremely high densities on the presynaptic membrane and synaptic vesicle $[17,40]$ (and below) - although this may be a fail-safe mechanism to ensure that synaptic transmission continues if endocytic recovery of vesicles is not $100 \%$ efficient $[41,42]$, NSF activity is compromised [43,44], or if a proportion of vesicle proteins are damaged and non-functional [45]. This is in line with the high SNARE density associated with vesicles involved in neurotransmitter release from cultured astrocytes (so-called gliotransmittters) $[46,47]$. However, it stands in direct contrast to endosomal fusion, where the SNARE density is substantially lower [48], perhaps reflecting the fact that recycling synaptic vesicles do not necessarily need to pass through an obligate sorting intermediate, to become competent for further rounds of fusion [49].

\subsection{SNARE localization and higher order structure: implications for function}

A large amount of experiment evidence, from studies of SNAREs in artificial membranes (liposomes) [50-52], or in a native lipid environment $[13,24,53,54]$, suggests that they are constitutively active 


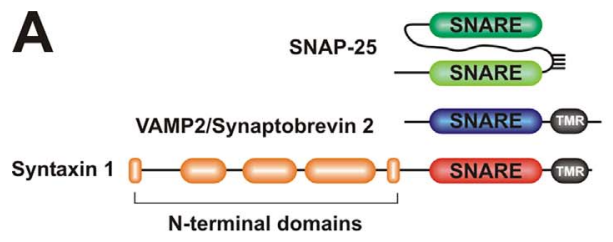

B
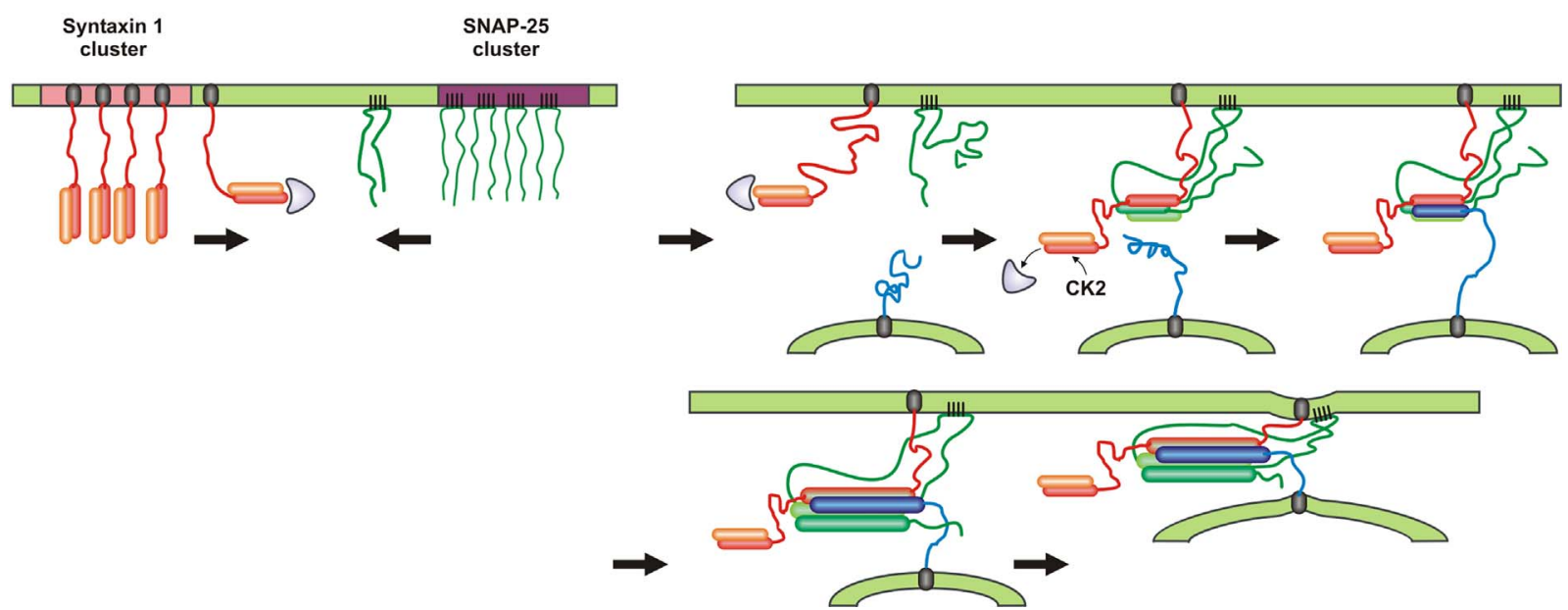

Fig. 2. SNAREs and SNARE-mediated membrane fusion.

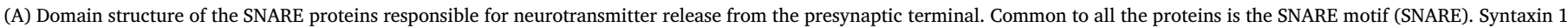

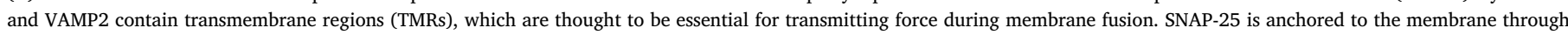

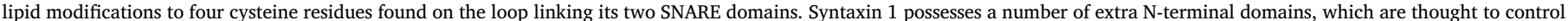
SNARE protein activity, by binding proteins such as Munc18 (see B, triangle shape; also see main text for details).

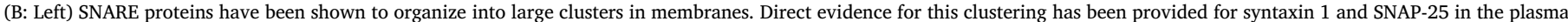

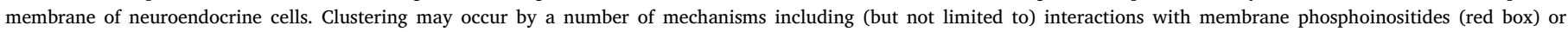

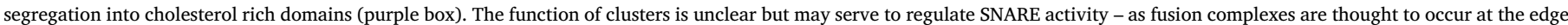

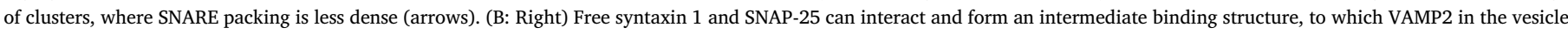

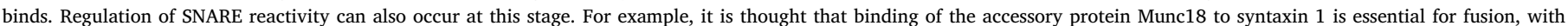

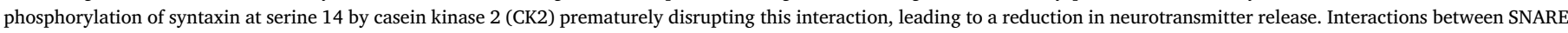

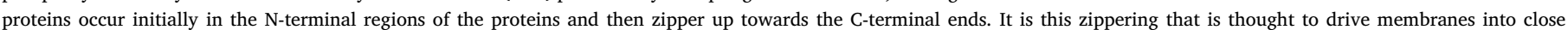

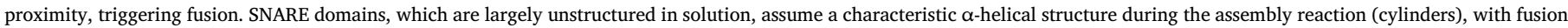
associated with the formation of a highly stable core complex, comprised of four parallel $\alpha$-helices. B (right side) is based on [142].

machines, implying the need for additional layers of control on the fusion machinery (see below). Although there have been reports that VAMP2 in vesicles is restricted from forming productive SNARE complexes with syntaxin and SNAP-25 because of its membrane association $[55,56]$, an alternative explanation is that the slow rate of fusion observed in these experiments reflects the lag between productive docking, complex initiation and fusion intrinsic to in vitro systems. The acceleration seen in the fusion rate on addition of synaptotagmin [57-60] is due merely to a $\mathrm{Ca}^{2+}$-dependent membrane bridging effect, leading to a greater probability of productive SNARE complex formation and fusion.

So, are SNAREs just blunt fusion machines? Historically, much of the data obtained onSNARE-mediated fusion has reported activity at the whole population level, which can obscure aspects of subtle regulation, that may actually have profound consequences on the fusion reaction. For example, there is strong evidence emerging that SNARE activity can be regulated by organization of SNAREs in the membrane. Microscopy studies using neuroendocrine PC12 cells suggest that both syntaxin and SNAP-25 on the plasma membrane cluster into partially overlapping domains of approximately $50 \mathrm{~nm}$ diameter, which contain between 30 to 70 SNARE proteins $[40,61]$. It has been proposed that clusters form and are maintained through a variety of mechanisms, including cholesterol-dependent SNARE partitioning [62], protein palmitoylation [63], hydrophobic mismatch [64], phosphorylation [65],
$\mathrm{Ca}^{2+}$-mediated SNARE-phosphoinositide interactions [66], homotypic SNARE-SNARE interactions [67], cytoskeletal anchoring [68] and heterotypic protein-protein interactions (such as between syntaxin 1 and Munc18) [69]. At present, the exact function(s) of SNARE clusters is/are unclear. The most obvious explanation is that they provide docking and fusion sites for vesicles. Although other functions cannot be excluded at this time, they seem secondary to the role of SNAREs in fusion. Critically, within these sites, higher order organization of SNARE proteins seems to play a role in controlling fusion activity. Fusion apparently takes place at the edge of SNARE clusters [70], where SNARE density is lowest $[70,71]$. Obviously, this implies that the SNARE proteins in the centre of clusters are sterically hindered from entering into fusion complexes (Fig. 2B). As such, any mechanism that regulates cluster size and SNARE density could regulate the fusion process, for instance by influencing whether membrane fusion adopts a 'kiss and run' or 'full fusion' pathway (see above). In this respect, the electrostatic interaction of syntaxin with phosphoinositides (mediated by $\mathrm{Ca}^{2+}$ influx during neurotransmitter release) may lead to a 'breathable' complex, which allows for rapid and reversible regulation of SNARE protein activity, depending on the level of stimulation and accumulated level of intracellular $\mathrm{Ca}^{2+}[72]$.

Synaptic vesicles contain, on average, 70 copies of the major SNARE protein VAMP2. Both biochemical and biophysical evidence suggests that VAMP2 also exists in clusters on the vesicle surface [73,74]. As a 
vesicle is essentially a small sphere that must navigate its way through the three-dimensional space of the cytoplasm in order to fuse with the plasma membrane, clustering of SNARE proteins implies that a vesicle needs to be orientated as it approaches the fusion apparatus. It is tempting to speculate that the vesicular ATPase plays such a role. This protein is generally thought to generate the proton electrochemical gradient needed for neurotransmitter uptake. However, it is present, on average, in just one copy [17] and has been shown to bind to both VAMP2 in the vesicle [73] and syntaxin 1 on the plasma membrane [75]. This means it would provide a unique orientation 'signature' on the vesicle. VAMP2 clustering on the membrane would then maximize fusion efficiency [31].

Early endosomes also possess SNARE clusters, which are sensitive to cholesterol depletion [76]. Although the precise functions of endosomes are debated [77], an attractive hypothesis is that they function as central relay stations for membrane recycling [78]. As such, it is hypothesized that they are connected to many different cellular compartments, including lysosomes, Golgi apparatus, and plasma membrane (including a role in the recycling of synaptic vesicles). To maintain fidelity in trafficking reactions, lateral segregation of SNAREs in the membrane has been proposed to provide one layer of specificity control, perhaps by acting in concert with proof reading mechanisms (see below).

\subsection{Do SNARE proteins encode specificity in the fusion reaction?}

Can SNAREs alone determine the specificity of a given fusion step? This is a contentious issue. Using a simple liposome preparation, incorporating various SNAREs found in the yeast secretory system, Rothman and colleagues have consistently reported that fusion only occurs between liposomes containing cognate SNAREs that can be assigned to distinct intracellular trafficking steps - including Golgi-plasma membrane, endoplasmic reticulum-Golgi, intra-Golgi, vacuole fusion and early endosome/trans-Golgi transport. This led them to propose that specificity is encoded in the fusion machinery itself, principally the SNARE motif [79-81]. However, this stands in direct contrast to a large body of work from other groups, indicating that SNARE proteins form promiscuous complexes. First, work using recombinant SNARE proteins (lacking transmembrane domains) has consistently shown that SNAREs can assemble promiscuously into core complexes in solution $[82,83]$. Second, there is redundancy between SNARE types: a SNAP-25 homologue (SNAP-23) [84] and VAMP2 homologue (VAMP3) [85] are capable of functionally substituting for their relatives in membrane fusion. Finally, the yeast SNARE Vti1p participates in multiple intracellular trafficking pathways [86,87]. At present, there is no explanation that adequately accounts for such disparate findings - with the balance of evidence supporting the fact that SNAREs can act promiscuously.

Given the high degree of structural conservation between core complexes $[22,25,88]$, it should not perhaps be too surprising that promiscuous complexes can form and provide sufficient energy for membrane fusion. However, this presents the issue of how specificity is maintained during membrane trafficking. This is especially important with organelles that participate in multiple fusion reactions, as exemplified by synaptic vesicles, which need to fuse both with the plasma membrane and endosomes at discrete points in their lifecycle - and as such possess multiple SNARE types (including VAMP2 and VAMP4) [17]. This led to a model in which formation of cognate complexes in trans is preferred but not absolute $[39,48]$, invoking an element of 'proof-reading' - perhaps through the activation of specific SNAREs by SM proteins (such as the syntaxin-Munc18 interaction, which is essential for synaptic vesicle fusion with the plasma membrane) $[53,89]$. An additional layer of control is proposed to be via lateral segregation of SNAREs into discrete sites on the membrane, which can serve to control the availability of SNAREs for cognate and non-cognate complexes (also see above). However, even this 'proof-reading' scheme cannot adequately explain specificity. Synaptic vesicles are not functionally equivalent. Presynaptic terminals contain distinct 'pools' of vesicles. Generally speaking, it is thought that these equate to a set of vesicles that is immediately available for release on stimulation (rapidly releasable pool: $\sim 5-8$ vesicles), an intermediate set which maintains release during moderate (physiological) stimulation (recycling pool: $\sim 17-20$ vesicles) and a set which is only released during intense (possibly non-physiological) stimulation (resting/reserve pool: $\sim 180$ vesicles) (reviewed extensively in [90]; note that an alternative view on the function of vesicles pools is given in [91]). At least a fraction of release competent reserve pool vesicles appear defined by SNARE composition, carrying VAMP7 instead of VAMP2 [92], implying that non-cognate SNARE complexes are functionally tolerated, and indeed physiologically necessary, under precisely defined conditions (although for a different explanation see [93]). Hence, this implies the existence of a hierarchical system, in which only vesicles carrying appropriate 'molecular tags' are trafficked to release sites, followed by a lower level of control through regulation of SNARE availability (segregation) and proof-reading.

\section{Specificity is achieved (partly) by higher order structure of the fusion site}

Assuming SNAREs are essentially constitutively active fusion machines, how is (spatial) specificity in the fusion reaction achieved particularly when SNARE clusters are distributed across the entire membrane [94]? Obviously, additional layers of control are needed. In part, this is provided by Rab proteins, which are generally considered to be key determinants of organellar identity in the secretory pathway. Key to their function is an elaborate GTPase cycle: Rab proteins exist either in a GTP-bound membrane associated configuration, or as a GDPbound cytosolic form [95]. When membrane bound to a trafficking organelle, Rab proteins can recruit motor proteins, which facilitate distribution along the cytoskeletal 'railroad' that spans the interior of the cell (for a full review on molecular motors and transport mechanisms see [96]). But this still does not answer the question of how a vesicle recognizes it has reached a release site and commits to fusion. There is growing evidence that release sites are marked by so-called 'tethering complexes' - which are large multi-subunit structures, which are stabilized at fusion sites by protein-protein and protein-lipid interactions [97] - and which effectively act to 'grab' vesicles and channel them to release sites. Like SNARE proteins, tethering complexes are found throughout the eukaryotic kingdom, with specific complexes marking specific trafficking steps [97]. Hence, the evolution of SNARE proteins and vesicle tethers seems to have co-evolved to generate specificity in the fusion reaction - although additional functions, such as the control of SNARE protein activity by tethering factors, cannot be excluded [97].

Of the multiple tethering complexes that exist, arguably the best characterized is the exocyst complex, which functions in constitutive (non $\mathrm{Ca}^{2+}$-dependent) fusion at the plasma membrane. The exocyst is found across eukaryotes, including in plants and yeast [98,99], and is highly expressed in the mammalian CNS. In the nervous system, the exocyst complex is associated primarily with neurite outgrowth and possibly synaptogenesis during development $[100,101]$, as well as remodeling of established circuits by plasma membrane modification through protein and/or lipid insertion [102,103] - a process which is distinct from involvement in neurotransmitter release [101,104] (and see below). The prevailing model of exocyst function is that the proteins Sec3 and Exo70 are bound to the plasma membrane through direct interaction(s) with $\mathrm{PIP}_{2}$, as well as with non-Rab GTPases, such as Cdc42 and Rho, which regulate the actin cytoskeleton (and, by default, will influence vesicle delivery to active sites of membrane expansion). A subcomplex consisting of the exocyst subunits Sec5, Sec6, Sec8, Sec10, Sec15 and Exo84 is recruited to secretory vesicles by the Rab protein Sec4 [97], although the precise point at which each individual subunit 
is recruited, and their precise contribution to the trafficking process, remains unclear (and could vary according to vesicle/cargo). It is the specific assembly of an intact exocyst complex, bridging the plasma membrane and trafficking vesicle, that drives tethering, prior to (nonspecific) SNARE-mediated fusion.

While components of the synaptic release machinery are initially trafficked to the presynapse from the cell body by active transport mechanisms (reviewed in [91]), recycling synaptic vesicles are, in contrast, already in situ. At a typical hippocampal synapse, the rapidly releasable pool of synaptic vesicles is effectively 'pre-recruited' and sits at the plasma membrane, waiting for an influx of $\mathrm{Ca}^{2+}$ to trigger fusion. In contrast, recycling and reserve pool vesicles occupy the cytosol of the presynaptic terminal. At rest, it appears that the majority of vesicles (principally the reserve pool) is largely immobile and physically prevented from participating in exocytosis, until prolonged periods of intense stimulation effectively force their recruitment, to maintain neurotransmitter release $[105,106]$. A popular concept is that these vesicles are immobilized by cross-linking to the actin cytoskeleton, with the most likely cross-linker being a member of the synapsin protein family (synapsin I) $[107,108]$. Synapsins are major phospho-proteins associated with synaptic vesicles [17]. Serine/threonine kinases linked to synapsin phosphorylation include cAMP-dependent protein kinase (PKA), $\mathrm{Ca}^{2+} /$ calmodulin-dependent protein kinases (CaMKI, CAMKII and CAMKIV) and mitogen-activated protein kinase/Erk (MAPK/Erk). Tyrosine phosphorylation is achieved through Src kinase [109]. Phosphorylation is opposed by the action of phosphatases, including protein phosphatase 2A (PP2A) and PP2B/calcineurin [109]. A general model of synapsin function proposes that an overall increase in serine phosphorylation promotes the dissociation of synapsin from synaptic vesicles and/or the actin meshwork, freeing them for fusion. Alternatively, threonine phosphorylation is thought to promote synapsin association and vesicle capture. This leads to the question of how these diametrically opposed effects can be reconciled. However, it needs to be remembered that while neuronal activity will trigger activation of various protein kinases and phosphatases, activation of the proteins will occur at different rates. In such a case, it is likely that intense stimulation initially leads to increased serine phosphorylation, releasing vesicles for exocytosis. In contrast, following endocytosis, tyrosine phosphorylation will predominate, trapping reformed vesicles and holding them in the reserve pool, ready for further rounds of release [110].

So, how do newly liberated vesicles find their way to the active zone for fusion? Microtubules do not penetrate into the presynaptic terminal, whereas studies in which the local actin cytoskeleton has been perturbed (usually by pharmacological manipulation) are contradictory, providing no clear answer as to whether active transport of vesicles is involved (reviewed in [91]). However, given the high density of vesicles in the presynapse, the small effective diffusion volume, the presence of a specialized tethering system (see below) and high local SNARE density, it is doubtful if a system operating on active transport (as opposed to diffusion) is actually needed to maintain exocytosis, especially under conditions of mild-to-moderate stimulation, where clearance of fusion sites by actin-mediated endocytosis, rather than vesicle supply, may actually be the rate-limiting step [111,112].

The cytoskeletal matrix assembled at active zones (CAZ) is a highly specialized tethering structure (conserved through evolution from worms to mammals) that appears to be specific to the process of regulated $\left(\mathrm{Ca}^{2+}\right.$-dependent) secretion, and is made up of a core set of proteins (illustrated in Fig. 3). Key players in the synaptic CAZ are RIM proteins [113]. RIM proteins are large multi-domain proteins, with various isoforms produced from four genes in combination with alternative splicing [114]. The long isoforms, RIM1 $\alpha$, RIM1 $\beta$ and RIM2 $\alpha$, are of particular interest for synaptic function ([114] and references therein), as they contain a N-terminal zinc finger domain, which was originally identified as a Rab3 effector (hence Rab3 Interacting Molecule: RIM). Four related isoforms of Rab3 are known (Rab3a, 3b, 3c and 3d). Rab3a is the predominant isoform in neurons and is localized to synaptic vesicles [17]. Prior to membrane fusion, Rab3 is vesicle associated: neurotransmitter release is associated with Rab3 loss [115]. As RIM proteins bind Rab3 in a GTP dependent fashion, this is strong evidence that RIM plays a key role in specifically recruiting fusion competent synaptic vesicles to active zones for fusion. In fact, transfection of the N-terminal zinc finger domain of RIM1 (which is responsible for Rab3 binding) into neurosecretory cells resulted in an increase in regulated exocytosis [116,117]. Recent reports suggest that a fraction of fusion competent synaptic vesicles also express Rab27b, which is exceptionally similar to Rab3a in both sequence and structure. This finding perhaps explains why Rab27b is also reported to bind RIM [118]. The extent to which differential Rab expression impacts on RIM related vesicle recruitment at the active zone is presently unknown.

In addition to its role in vesicle recruitment, RIM also serves additional important functions, including clustering $\mathrm{Ca}^{2+}$ channels and recruitment of Munc13 (which is thought to be an essential priming factor for synaptic vesicles) (see Fig. 3). However, a detailed discussion of these additional functions is beyond the scope of this article. Instead the reader is directed to an excellent recent review [119]. Variations on the CAZ are thought to play a play in other specialized secretory systems, including astrocytes [120], chromaffin cells [121], pancreas [122] and mast cells [123].

Recently endocytosed synaptic vesicles are highly mobile within the synaptic terminal [106], while theendosome itself may be dynamically positioned by active transport [124]. So, how is specific fusion between a recycling vesicle and an endosome achieved? It is likely that a similar Rab-based system is involved. Rab5 is present on vesicles and has previously been implicated in synaptic vesicle recycling $[125,126]$. In fact, disruption of the Rab5 GTPase cycle correlates with morphological disturbances in vesicle-recycling intermediates and synaptic vesicle pools [127,128]. Rab5 effectors, such as early endosome antigen 1 (EEA1) and Rabaptin-5/Rabex-5, are known to localize to early endosomes, where they form high molecular weight complexes with NSF and the SNAREs syntaxin 13 and syntaxin $6[129,130]$. Obviously, it is tempting to extrapolate and think that differential recruitment of individual Rab proteins to a vesicle indicates the specific point it has reached in the recycling pathway. Consistent with this hypothesis, multiple Rab proteins are actually known to co-purify with bulk isolated synaptic vesicles [131]. Furthermore, such interconversion of Rab status is, in fact, known to occur on endosomes with localization of Rab4, Rab5 and Rab11 to specific membrane microdomains indicative of an endosomal maturation process [132].

The precise role of endosomal sorting remains unclear, but the idea of a sorting station remains attractive, as it provides a step in which old, or damaged, vesicle components can be removed and sent to the lysosome for degradation (via a Rab35-mediated pathway [133]), while simultaneously allowing for incorporation of new components (transported from the cell body). Fully functional synaptic vesicles can then be reformed (a process which may, or may not, involve clathrinmediated budding), before being refilled with neurotransmitter and made ready for further rounds of exocytosis. It is unclear whether endosomal trafficking is involved in the regeneration of all vesicles, or just a distinct subset, which may or may not relate to the functional pool from which they originated [134], and which might result in spatial segregation (based on endosome position) in the presynaptic terminal $[134,135]$.

\section{Does regulation of vesicle fusion contribute to synaptic plasticity?}

Synaptic plasticity is the ability of synapses to strengthen or weaken over time. Short-term synaptic plasticity results from an increased or decreased probability of synaptic terminals releasing transmitters in response to presynaptic action potentials. Could (reversible) changes in the membrane trafficking pathway, and hence vesicle supply, contribute to such a phenomenon? Here, I will speculate on such 


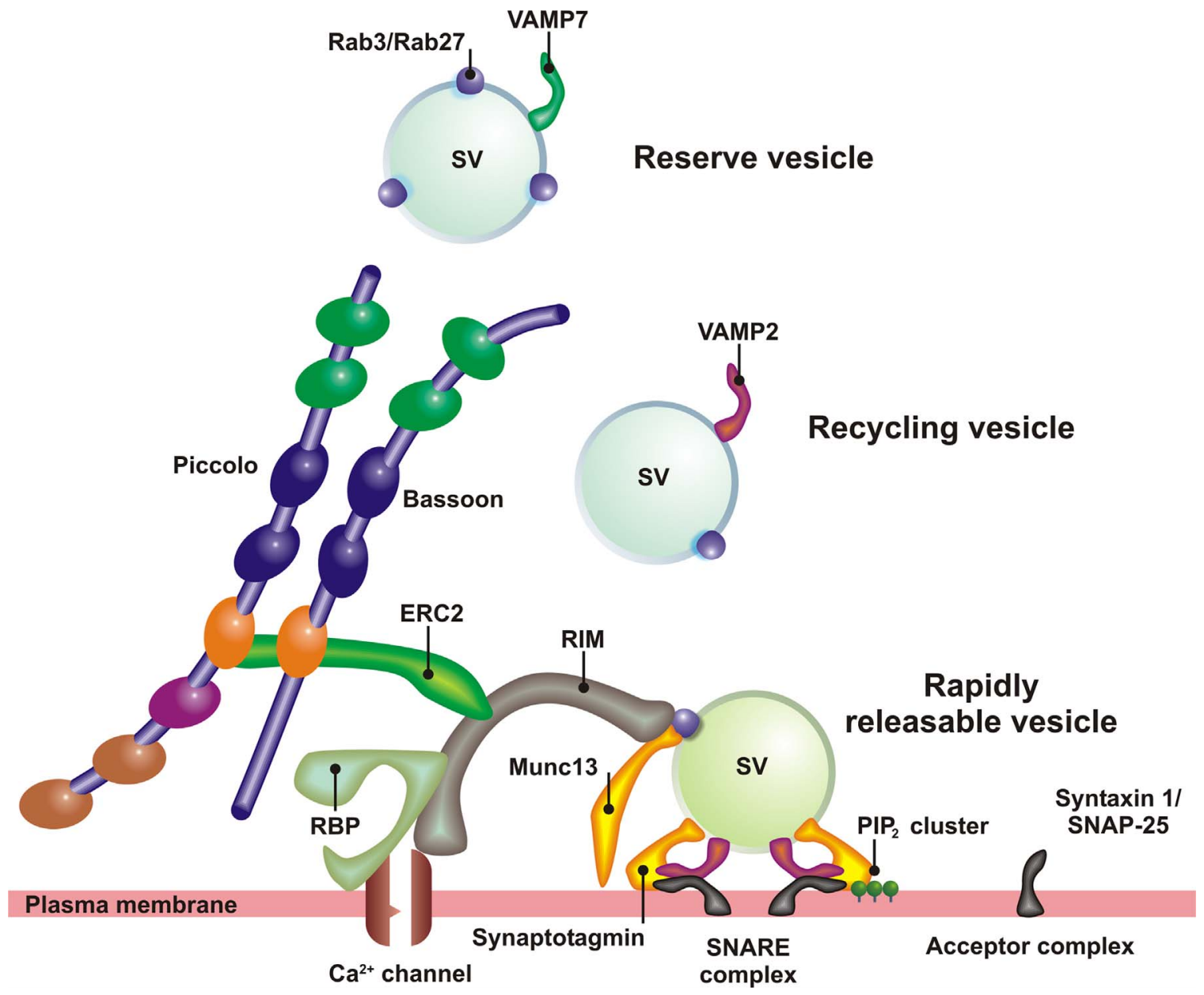

Fig. 3. Molecular organization of the active zone is thought to confer a level of specificity to the fusion reaction.

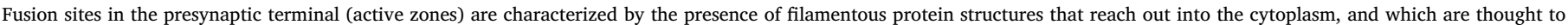

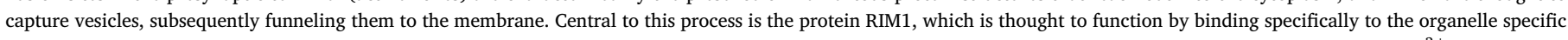

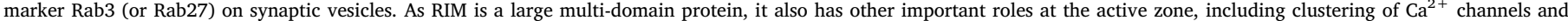

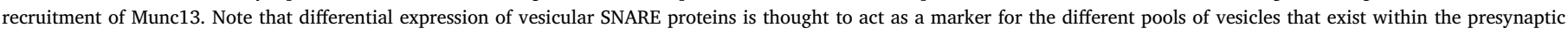

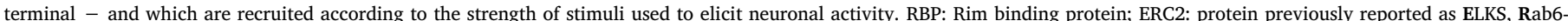

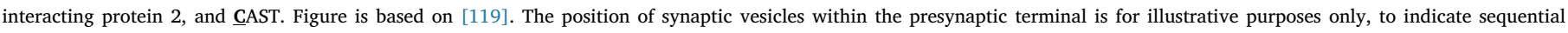
recruitment of vesicle pools based on the intensity of stimulation. In reality, such a strict spatial segregation of vesicle pools may not exist.

mechanisms and illustrate with relevant examples. These will be characterized as 'immediate', 'intermediate' and 'long-term' to indicate the relative timescales over which such alterations are likely to take place.

First and most simple, the availability of SNARE proteins for fusion is likely to be a key determinant of release probability. One likely method is to control access to proteins through steric mechanisms [70], with electrostatic modulation of SNARE clusters through $\mathrm{Ca}^{2+}$-mediated interactions with phosphoinositides $[66,72]$ providing a simple and quick, or 'immediate', modulatory mechanism (and see above). However, proof that such membrane reorganization occurs on biologically relevant timescales is still lacking.

Post-translational modification of SNAREs may also play a role in regulating activity. This may be via a variety of mechanisms. For example, (reversible) palmitoylation may control SNARE numbers and accessibility, through trafficking to cholesterol rich domains [136,137]. Phosphorylation of SNAREs has also been reported to regulate activity, through modification of protein-protein interactions during the fusion process $[138,139]$. For example, phosphorylation of syntaxin 1 at serine 14 by casein kinase 2 disrupts the syntaxin-Munc18 interaction, leading to reduced secretion [140]. Given that post-translational modifications are generally enzyme mediated, it is likely that these events take place over 'intermediate' timescales.
At the polar extreme, fusion at the plasma membrane is believed to be limited by the number of available fusion 'slots' [111]. Presumably, this is reflected by the size of the presynaptic active zone [141]. RIM1 and 2 (as well as other active zone components) are thought to be trafficked to synapses on specialized transport vesicles, which insert into the presynaptic membrane, forming de novo active zones during development, or increasing active zone size and synaptic strength at later times. Likewise, removal of whole active zones, or critical protein components, would serve to decrease neurotransmitter release [119]. The cellular logistics underlying whole-scale active zone modification (s) are such that these effects are likely to be 'long-term', compared to the other mechanisms postulated.

Given that an increase or decrease in vesicle fusion would also impact recycling, it is likely that analogous processes occur in the endosome system, to tune recycling capacity to the functional demands of the synapse.

\section{Conclusions and outlook}

There is compelling evidence that membrane fusion at the synapse is executed by the reversible formation of SNARE complexes. Although there is a general consensus as to the basic mechanism of SNARE action, there remain many questions to be answered. Primary amongst these 
are the regulatory elements that control SNARE activity, permit specificity in the fusion event and tune synaptic output. Such regulation occurs at many different levels, and it is likely that many potential modifiers have yet to be identified - let alone a detailed mechanistic understanding of their action obtained. Understanding these layers of regulation, and how they contribute to synaptic function, will be one of the main challenges in the years ahead. It is likely that these advances will be generally applicable across the range of membrane trafficking events found throughout eukaryotes, thus illuminating our knowledge of this universal process.

\section{Acknowledgements}

MGH acknowledges David Pennington, who provided artwork for all figures. Dr. Felipe Zilly provided critical comments on the manuscript. Ian Hutchinson, Michael Dunlop and Michael Rutter provided encouragement. MGH is funded by VIB institutional support and grants from the European Research Council (281961 and 713755), FWO (G066715N and G088415N), Thierry Latran Foundation and SAO (S16025). MGH apologizes to all colleagues whose work could not be cited and discussed due to space limitations.

\section{References}

[1] M. Aridor, L.A. Hannan, Traffic jam: a compendium of human diseases that affect intracellular transport processes, Traffic 1 (2000) 836-851.

[2] R. Jahn, R.H. Scheller, SNAREs - engines for membrane fusion, Nat. Rev. Mol. Cell Biol. 7 (2006) 631-643.

[3] R. Jahn, T.C. Südhof, Synaptic vesicle traffic: rush hour in the nerve terminal, J. Neurochem. 61 (1993) 12-21.

[4] J.L. Goldstein, M.S. Brown, R.G. Anderson, D.W. Russell, W.J. Schneider, Receptor-mediated endocytosis: concepts emerging from the LDL receptor system, Annu. Rev. Cell Biol. 1 (1985) 1-39.

[5] N.B. Hamilton, D. Attwell, Do astrocytes really exocytose neurotransmitters? Nat. Rev. Neurosci. 11 (2010) 227-238.

[6] L. Li, L.S. Chin, The molecular machinery of synaptic vesicle exocytosis, Cell. Mol. Life Sci. 60 (2003) 942-960.

[7] M. Ohara-Imaizumi, T. Ohtsuka, S. Matsushima, Y. Akimoto, C. Nishiwaki, Y. Nakamichi, T. Kikuta, S. Nagai, H. Kawakami, T. Watanabe, S. Nagamatsu, ELKS, a protein structurally related to the active zone-associated protein CAST, is expressed in pancreatic beta cells and functions in insulin exocytosis: interaction of ELKS with exocytotic machinery analyzed by total internal reflection fluorescence microscopy, Mol. Biol. Cell 16 (2005) 3289-3300.

[8] A.H. Tang, H. Chen, T.P. Li, S.R. Metzbower, H.D. MacGillavry, T.A. Blanpied, A trans-synaptic nanocolumn aligns neurotransmitter release to receptors, Nature 536 (2016) 210-214.

[9] S. Watanabe, B.R. Rost, M. Camacho-Pérez, M.W. Davis, B. Söhl-Kielczynski, C. Rosenmund, E.M. Jorgensen, Ultrafast endocytosis at mouse hippocampal synapses, Nature 504 (2013) 242-247.

[10] B. Granseth, B. Odermatt, S.J. Royle, L. Lagnado, Clathrin-mediated endocytosis is the dominant mechanism of vesicle retrieval at hippocampal synapses, Neuron 51 (2006) 773-786.

[11] J.C. Nicholson-Fish, A.C. Kokotos, T.H. Gillingwater, K.J. Smillie, M.A. Cousin, VAMP4 is an essential cargo molecule for activity-dependent bulk endocytosis, Neuron 88 (2015) 973-984.

[12] T.C. Südhof, The synaptic vesicle cycle: a cascade of protein-protein interactions, Nature 375 (1995) 645-653.

[13] M. Holt, D. Riedel, A. Stein, C. Schuette, R. Jahn, Synaptic vesicles are constitutively active fusion machines that function independently of $\mathrm{Ca}^{2+}$, Curr. Biol. 18 (2008) 715-722.

[14] L.V. Chernomordik, M.M. Kozlov, Mechanics of membrane fusion, Nat. Struct. Mol. Biol. 15 (2008) 675-683,

[15] V.S. Malinin, P. Frederik, B.R. Lentz, Osmotic and curvature stress affect PEGinduced fusion of lipid vesicles but not mixing of their lipids, Biophys. J . 82 (2002) 2090-2100.

[16] D.L. Daleke, Regulation of transbilayer plasma membrane phospholipid asymmetry, J. Lipid Res. 44 (2003) 233-242.

[17] S. Takamori, M. Holt, K. Stenius, E.A. Lemke, M. Grønborg, D. Riedel, H. Urlaub, S. Schenck, B. Brügger, P. Ringler, S.A. Müller, B. Rammner, F. Gräter, J.S. Hub, B.L. De Groot, G. Mieskes, Y. Moriyama, J. Klingauf, H. Grubmüller, J. Heuser, F. Wieland, R. Jahn, Molecular anatomy of a trafficking organelle, Cell 127 (2006) 831-846.

[18] V.A. Klyachko, M.B. Jackson, Capacitance steps and fusion pores of small and large-dense-core vesicles in nerve terminals, Nature 418 (2002) 89-92.

[19] C. Imig, S.W. Min, S. Krinner, M. Arancillo, C. Rosenmund, T.C. Südhof, J. Rhee, N. Brose, B.H. Cooper, The morphological and molecular nature of synaptic vesicle priming at presynaptic active zones, Neuron 84 (2014) 416-431.

[20] D. Fasshauer, M. Margittai, A transient N-terminal interaction of SNAP-25 and syntaxin nucleates SNARE assembly, J. Biol. Chem. 279 (2004) 7613-7621.

[21] Y. Gao, S. Zorman, G. Gundersen, Z. Xi, L. Ma, G. Sirinakis, J.E. Rothman, Y. Zhang, Single reconstituted neuronal SNARE complexes zipper in three distinct stages, Science 337 (2012) 1340-1343.

[22] A. Stein, G. Weber, M.C. Wahl, R. Jahn, Helical extension of the neuronal SNARE complex into the membrane, Nature 460 (2009) 525-528.

[23] J.K. Ryu, D. Min, S.H. Rah, S.J. Kim, Y. Park, H. Kim, C. Hyeon, H.M. Kim, R. Jahn, T.Y. Yoon, Spring-loaded unraveling of a single SNARE complex by NSF in one round of ATP turnover, Science 347 (2015) 1485-1489.

[24] T. Lang, M. Margittai, H. Hölzler, R. Jahn, SNAREs in native plasma membranes are active and readily form core complexes with endogenous and exogenous SNARES, J. Cell Biol. 158 (2002) 751-760.

[25] D. Zwilling, A. Cypionka, W.H. Pohl, D. Fasshauer, P.J. Walla, M.C. Wahl, R. Jahn, Early endosomal SNAREs form a structurally conserved SNARE complex and fuse liposomes with multiple topologies, EMBO J. 26 (2007) 9-18.

[26] S.S. Krishnakumar, F. Li, J. Coleman, C.M. Schauder, D. Kümmel, F. Pincet, J.E. Rothman, K.M. Reinisch, Re-visiting the trans insertion model for complexin clamping, Elife 4 (2015).

[27] Q. Zhou, P. Zhou, A.L. Wang, D. Wu, M. Zhao, T.C. Südhof, A.T. Brunger, The primed SNARE-complexin-synaptotagmin complex for neuronal exocytosis, Nature 548 (2017) 420-425.

[28] Y. Kozlovsky, M.M. Kozlov, Stalk model of membrane fusion: solution of energy crisis, Biophys. J . 82 (2002) 882-895.

[29] D.P. Siegel, M.M. Kozlov, The gaussian curvature elastic modulus of N-monomethylated dioleoylphosphatidylethanolamine: relevance to membrane fusion and lipid phase behavior, Biophys. J . 87 (2004) 366-374.

[30] R. Mohrmann, H. de Wit, M. Verhage, E. Neher, J.B. Sørensen, Fast vesicle fusion in living cells requires at least three SNARE complexes, Science 330 (2010) $502-505$.

[31] J.M. Hernandez, A.J. Kreutzberger, V. Kiessling, L.K. Tamm, R. Jahn, Variable cooperativity in SNARE-mediated membrane fusion, Proc. Natl. Acad. Sci. U. S. A 111 (2014) 12037-12042.

[32] D. Puchkov, V. Haucke, Greasing the synaptic vesicle cycle by membrane lipids, Trends Cell Biol. 23 (2013) 493-503.

[33] C. Francois-Martin, J.E. Rothman, F. Pincet, Low energy cost for optimal speed and control of membrane fusion, Proc. Natl. Acad. Sci. U. S. A. 114 (2017) 1238-1241.

[34] H.T. McMahon, M.M. Kozlov, S. Martens, Membrane curvature in synaptic vesicle fusion and beyond, Cell 140 (2010) 601-605.

[35] R. Sinha, S. Ahmed, R. Jahn, J. Klingauf, Two synaptobrevin molecules are sufficient for vesicle fusion in central nervous system synapses, Proc. Natl. Acad. Sci. U. S. A. 108 (2011) 14318-14323.

[36] X. Han, C.T. Wang, J. Bai, E.R. Chapman, M.B. Jackson, Transmembrane segments of syntaxin line the fusion pore of $\mathrm{Ca}^{2+}$-triggered exocytosis, Science 304 (2004) 289-292.

[37] Z. Wu, O.D. Bello, S. Thiyagarajan, S.M. Auclair, W. Vennekate, S.S. Krishnakumar, B. O'Shaughnessy, E. Karatekin, Dilation of fusion pores by crowding of SNARE proteins, Elife 6 (2017).

[38] A. Guček, J. Jorgačevski, P. Singh, C. Geisler, M. Lisjak, N. Vardjan, M. Kreft, A. Egner, R. Zorec, Dominant negative SNARE peptides stabilize the fusion pore in a narrow, release-unproductive state, Cell. Mol. Life Sci. 73 (2016) 3719-3731.

[39] J. Jorgačevski, M. Potokar, S. Grilc, M. Kreft, W. Liu, J.W. Barclay, J. Bückers, R. Medda, S.W. Hell, V. Parpura, R.D. Burgoyne, R. Zorec, Munc18-1 tuning of vesicle merger and fusion pore properties, J. Neurosci. 31 (2011) 9055-9066.

[40] J.J. Sieber, K.I. Willig, R. Heintzmann, S.W. Hell, T. Lang, The SNARE motif is essential for the formation of syntaxin clusters in the plasma membrane, Biophys. J. 90 (2006) 2843-2851.

[41] C. Walch-Solimena, J. Blasi, L. Edelmann, E.R. Chapman, G.F. von Mollard, R. Jahn, The t-SNARES syntaxin 1 and SNAP-25 are present on organelles that participate in synaptic vesicle recycling, J. Cell Biol. 128 (1995) 637-645.

[42] M. Wienisch, J. Klingauf, Vesicular proteins exocytosed and subsequently retrieved by compensatory endocytosis are nonidentical, Nat. Neurosci. 9 (2006) 1019-1027.

[43] H. Otto, P.I. Hanson, R. Jahn, Assembly and disassembly of a ternary complex of synaptobrevin, syntaxin, and SNAP-25 in the membrane of synaptic vesicles, Proc. Natl. Acad. Sci. U. S. A. 94 (1997) 6197-6201.

[44] J.T. Littleton, E.R. Chapman, R. Kreber, M.B. Garment, S.D. Carlson, B. Ganetzky, Temperature-sensitive paralytic mutations demonstrate that synaptic exocytosis requires SNARE complex assembly and disassembly, Neuron 21 (1998) 401-413.

[45] V. Uytterhoeven, S. Kuenen, J. Kasprowicz, K. Miskiewicz, P. Verstreken, Loss of skywalker reveals synaptic endosomes as sorting stations for synaptic vesicle proteins, Cell 145 (2011) 117-132.

[46] V. Schubert, D. Bouvier, A. Volterra, SNARE protein expression in synaptic terminals and astrocytes in the adult hippocampus: a comparative analysis, Glia 59 (2011) 1472-1488.

[47] P. Singh, J. Jorgačevski, M. Kreft, V. Grubišić, R.F. Stout Jr., M. Potokar, V. Parpura, R. Zorec, Single-vesicle architecture of synaptobrevin 2 in astrocytes, Nat. Commun. 5 (2014) 3780.

[48] I. Bethani, T. Lang, U. Geumann, J.J. Sieber, R. Jahn, S.O. Rizzoli, The specificity of SNARE pairing in biological membranes is mediated by both proof-reading and spatial segregation, EMBO J. 26 (2007) 3981-3992.

[49] V.N. Murthy, C.F. Stevens, Synaptic vesicles retain their identity through the en docytic cycle, Nature 392 (1998) 497-501.

[50] T. Weber, B.V. Zemelman, J.A. McNew, B. Westermann, M. Gmachl, F. Parlati, T.H. Söllner, J.E. Rothman, SNAREpins: minimal machinery for membrane fusion, Cell 92 (1998) 759-772.

[51] M. Holt, F. Varoqueaux, K. Wiederhold, S. Takamori, H. Urlaub, D. Fasshauer, 
R. Jahn, Identification of SNAP-47, a novel Qbc-SNARE with ubiquitous expression, J. Biol. Chem. 281 (2006) 17076-17083.

[52] T.J. Siddiqui, O. Vites, A. Stein, R. Heintzmann, R. Jahn, D. Fasshauer, Determinants of synaptobrevin regulation in membranes, Mol. Biol. Cell 18 (2007) 2037-2046.

[53] F.E. Zilly, J.B. Sørensen, R. Jahn, T. Lang, Munc18-bound syntaxin readily forms SNARE complexes with synaptobrevin in native plasma membranes, PLoS Biol. 4 (2006) e330.

[54] Y. Park, J.M. Hernandez, G. van den Bogaart, S. Ahmed, M. Holt, D. Riedel, R. Jahn, Controlling synaptotagmin activity by electrostatic screening, Nat. Struct. Mol. Biol. 19 (2012) 991-997.

[55] K. Hu, J. Carroll, S. Fedorovich, C. Rickman, A. Sukhodub, B. Davletov, Vesicular restriction of synaptobrevin suggests a role for calcium in membrane fusion, Nature 415 (2002) 646-650.

[56] D.H. Kweon, C.S. Kim, Y.K. Shin, Regulation of neuronal SNARE assembly by the membrane, Nat. Struct. Biol. 10 (2003) 440-447.

[57] W.C. Tucker, T. Weber, E.R. Chapman, Reconstitution of $\mathrm{Ca}^{2+}$-regulated membrane fusion by synaptotagmin and SNAREs, Science 304 (2004) 435-438.

[58] D. Araç, X. Chen, H.A. Khant, J. Ubach, S.J. Ludtke, M. Kikkawa, A.E. Johnson, W. Chiu, T.C. Südhof, J. Rizo, Close membrane-membrane proximity induced by $\mathrm{Ca}^{2+}$-dependent multivalent binding of synaptotagmin-1 to phospholipids, Nat. Struct. Mol. Biol. 13 (2006) 209-217.

[59] W. Kuo, D.Z. Herrick, D.S. Cafiso, Phosphatidylinositol 4,5-bisphosphate alters synaptotagmin 1 membrane docking and drives opposing bilayers closer together, Biochemistry 50 (2011) 2633-2641.

[60] G. van den Bogaart, S. Thutupalli, J.H. Risselada, K. Meyenberg, M. Holt, D. Riedel, U. Diederichsen, S. Herminghaus, H. Grubmüller, R. Jahn, Synaptotagmin-1 may be a distance regulator acting upstream of SNARE nucleation, Nat. Struct. Mol. Biol. 18 (2011) 805-812.

[61] C. Rickman, C.N. Medine, A.R. Dun, D.J. Moulton, O. Mandula, N.D. Halemani, S.O. Rizzoli, L.H. Chamberlain, R.R. Duncan, t-SNARE protein conformations patterned by the lipid microenvironment, J. Biol. Chem. 285 (2010) 13535-13541.

[62] T. Lang, D. Bruns, D. Wenzel, D. Riedel, P. Holroyd, C. Thiele, R. Jahn, SNAREs are concentrated in cholesterol-dependent clusters that define docking and fusion sites for exocytosis, EMBO J. 20 (2001) 2202-2213.

[63] R. Kang, J. Wan, P. Arstikaitis, H. Takahashi, K. Huang, A.O. Bailey, J.X. Thompson, A.F. Roth, R.C. Drisdel, R. Mastro, W.N. Green, J.R. Yates 3rd, N.G. Davis, A. El-Husseini, Neural palmitoyl-proteomics reveals dynamic synaptic palmitoylation, Nature 456 (2008) 904-909.

[64] D. Milovanovic, A. Honigmann, S. Koike, F. Göttfert, G. Pähler, M. Junius, S. Müllar, U. Diederichsen, A. Janshoff, H. Grubmüller, H.J. Risselada, C. Eggeling, S.W. Hell, G. van den Bogaart, R. Jahn, Hydrophobic mismatch sorts SNARE proteins into distinct membrane domains, Nat. Commun. 6 (2015) 5984.

[65] D.L. Foletti, R. Lin, M.A. Finley, R.H. Scheller, Phosphorylated syntaxin 1 is localized to discrete domains along a subset of axons, J. Neurosci. 20 (2000) $4535-4544$.

[66] D. Milovanovic, M. Platen, M. Junius, U. Diederichsen, I.A. Schaap, A. Honigmann, R. Jahn, G. van den Bogaart, Calcium promotes the formation of syntaxin 1 mesoscale domains through phosphatidylinositol 4,5-bisphosphate, J. Biol. Chem. 291 (2016) 7868-7876.

[67] J.J. Sieber, K.I. Willig, C. Kutzner, C. Gerding-Reimers, B. Harke, G. Donnert, B. Rammner, C. Eggeling, S.W. Hell, H. Grubmüller, T. Lang, Anatomy and dynamics of a supramolecular membrane protein cluster, Science 317 (2007) $1072-1076$.

[68] C.J. Torregrosa-Hetland, J. Villanueva, V. Garcia-Martínez, G. Expósito-Romero, M. Francés Mdel, L.M. Gutiérrez, Cortical F-actin affects the localization and dynamics of SNAP-25 membrane clusters in chromaffin cells, Int. J. Biochem. Cell Biol. 45 (2013) 583-592.

[69] R.F. Toonen, O. Kochubey, H. de Wit, A. Gulyas-Kovacs, B. Konijnenburg, J.B. Sørensen, J. Klingauf, M. Verhage, Dissecting docking and tethering of secretory vesicles at the target membrane, EMBO J. 25 (2006) 3725-3737.

[70] L. Yang, A.R. Dun, K.J. Martin, Z. Qiu, A. Dunn, G.J. Lord, W. Lu, R.R. Duncan, C. Rickman, Secretory vesicles are preferentially targeted to areas of low molecular SNARE density, PLoS One 7 (2012) e49514.

[71] D. Bar-On, S. Wolter, S. van de Linde, M. Heilemann, G. Nudelman, E. Nachliel, M. Gutman, M. Sauer, U. Ashery, Super-resolution imaging reveals the internal architecture of nano-sized syntaxin clusters, J. Biol. Chem. 287 (2012) 27158-27167.

[72] F.E. Zilly, N.D. Halemani, D. Walrafen, L. Spitta, A. Schreiber, R. Jahn, T. Lang, $\mathrm{Ca}^{2+}$ induces clustering of membrane proteins in the plasma membrane via electrostatic interactions, EMBO J. 30 (2011) 1209-1220.

[73] M.K. Bennett, N. Calakos, T. Kreiner, R.H. Scheller, Synaptic vesicle membrane proteins interact to form a multimeric complex, J. Cell Biol. 116 (1992) 761-775.

[74] S. Castorph, D. Riedel, L. Arleth, M. Sztucki, R. Jahn, M. Holt, T. Salditt, Structure parameters of synaptic vesicles quantified by small-angle $\mathrm{x}$-ray scattering, Biophys. J . 98 (2010) 1200-1208.

[75] P.R. Hiesinger, A. Fayyazuddin, S.Q. Mehta, T. Rosenmund, K.L. Schulze, R.G. Zhai, P. Verstreken, Y. Cao, Y. Zhou, J. Kunz, H.J. Bellen, The v-ATPase V0 subunit a1 is required for a late step in synaptic vesicle exocytosis in Drosophila, Cell 121 (2005) 607-620.

[76] U. Geumann, C. Schäfer, D. Riedel, R. Jahn, S.O. Rizzoli, Synaptic membrane proteins form stable microdomains in early endosomes, Microsc. Res. Tech. 73 (2010) 606-617.

[77] S. Jähne, S.O. Rizzoli, M.S. Helm, The structure and function of presynaptic endosomes, Exp. Cell Res. 335 (2015) 172-179.
[78] D. Brandhorst, D. Zwilling, S.O. Rizzoli, U. Lippert, T. Lang, R. Jahn, Homotypic fusion of early endosomes: SNAREs do not determine fusion specificity, Proc. Natl. Acad. Sci. U. S. A. 103 (2006) 2701-2706.

[79] F. Paumet, V. Rahimian, J.E. Rothman, The specificity of SNARE-dependent fusion is encoded in the SNARE motif, Proc. Natl. Acad. Sci. U. S. A. 101 (2004) 3376-3380.

[80] F. Parlati, J.A. McNew, R. Fukuda, R. Miller, T.H. Söllner, J.E. Rothman, Topological restriction of SNARE-dependent membrane fusion, Nature 407 (2000) 194-198.

[81] J.A. McNew, F. Parlati, R. Fukuda, R.J. Johnston, K. Paz, F. Paumet, T.H. Söllner, J.E. Rothman, Compartmental specificity of cellular membrane fusion encoded in SNARE proteins, Nature 407 (2000) 153-159.

[82] D. Fasshauer, W. Antonin, M. Margittai, S. Pabst, R. Jahn, Mixed and non-cognate SNARE complexes. Characterization of assembly and biophysical properties, J. Biol. Chem. 274 (1999) 15440-15446.

[83] B. Yang, L. Gonzalez Jr., R. Prekeris, M. Steegmaier, R.J. Advani, R.H. Scheller SNARE interactions are not selective. Implications for membrane fusion specificity, J. Biol. Chem. 274 (1999) 5649-5653.

[84] J.B. Sørensen, G. Nagy, F. Varoqueaux, R.B. Nehring, N. Brose, M.C. Wilson, E. Neher, Differential control of the releasable vesicle pools by SNAP-25 splice variants and SNAP-23, Cell 114 (2003) 75-86.

[85] M. Borisovska, Y. Zhao, Y. Tsytsyura, N. Glyvuk, S. Takamori, U. Matti, J. Rettig, T. Südhof, D. Bruns, v-SNAREs control exocytosis of vesicles from priming to fusion, EMBO J. 24 (2005) 2114-2126.

[86] G.F. von Mollard, S.F. Nothwehr, T.H. Stevens, The yeast v-SNARE Vti1p mediate two vesicle transport pathways through interactions with the t-SNAREs Sed5p and Pep12p, J. Cell Biol. 137 (1997) 1511-1524.

[87] G. Fischer von Mollard, T.H. Stevens, The Saccharomyces cerevisiae v-SNARE Vtilp is required for multiple membrane transport pathways to the vacuole, Mol. Biol. Cell 10 (1999) 1719-1732.

[88] W. Antonin, D. Fasshauer, S. Becker, R. Jahn, T.R. Schneider, Crystal structure of the endosomal SNARE complex reveals common structural principles of all SNAREs, Nat. Struct. Biol. 9 (2002) 107-111.

[89] J. Shen, D.C. Tareste, F. Paumet, J.E. Rothman, T.J. Melia, Selective activation of cognate SNAREpins by Sec1/Munc18 proteins, Cell 128 (2007) 183-195.

[90] S.O. Rizzoli, W.J. Betz, Synaptic vesicle pools, Nat. Rev. Neurosci. 6 (2005) 57-69.

[91] S.O. Rizzoli, Synaptic vesicle recycling: steps and principles, EMBO J. 33 (2014) 788-822.

[92] Z. Hua, S. Leal-Ortiz, S.M. Foss, C.L. Waites, C.C. Garner, S.M. Voglmaier, R.H. Edwards, v-SNARE composition distinguishes synaptic vesicle pools, Neuron 71 (2011) 474-487.

[93] S. Truckenbrodt, S.O. Rizzoli, Spontaneous vesicle recycling in the synaptic bouton, Front. Cell. Neurosci. 8 (2014) 409.

[94] C. Duc, S. Catsicas, Ultrastructural localization of SNAP-25 within the rat spinal cord and peripheral nervous system, J. Comp. Neurol. 356 (1995) 152-163.

[95] J.B. Bock, H.T. Matern, A.A. Peden, R.H. Scheller, A genomic perspective on membrane compartment organization, Nature 409 (2001) 839-841.

[96] N. Hirokawa, S. Niwa, Y. Tanaka, Molecular motors in neurons: transport mechanisms and roles in brain function, development, and disease, Neuron 68 (2010) 610-638.

[97] I.M. Yu, F.M. Hughson, Tethering factors as organizers of intracellular vesicular traffic, Annu. Rev. Cell Dev. Biol. 26 (2010) 137-156.

[98] K. Ebine, T. Ueda, Roles of membrane trafficking in plant cell wall dynamics, Front. Plant Sci. 6 (2015) 878.

[99] D. Mukherjee, A. Sen, R.C. Aguilar, RhoGTPase-binding proteins, the exocyst complex and polarized vesicle trafficking, Small GTPases 5 (2014) e28453.

[100] S.Q. Mehta, P.R. Hiesinger, S. Beronja, R.G. Zhai, K.L. Schulze, P. Verstreken, Y. Cao, Y. Zhou, U. Tepass, M.C. Crair, H.J. Bellen, Mutations in Drosophila sec15 reveal a function in neuronal targeting for a subset of exocyst components, Neuron 46 (2005) 219-232.

[101] D.B. Schwenger, T. Kuner, Acute genetic perturbation of exocyst function in the rat calyx of Held impedes structural maturation, but spares synaptic transmission, Eur. J. Neurosci. 32 (2010) 974-984.

[102] N. Sans, K. Prybylowski, R.S. Petralia, K. Chang, Y.X. Wang, C. Racca, S. Vicini, R.J. Wenthold, NMDA receptor trafficking through an interaction between PDZ proteins and the exocyst complex, Nat. Cell Biol. 5 (2003) 520-530.

[103] N.Z. Gerges, D.S. Backos, C.N. Rupasinghe, M.R. Spaller, J.A. Esteban, Dual role of the exocyst in AMPA receptor targeting and insertion into the postsynaptic membrane, EMBO J. 25 (2006) 1623-1634.

[104] M. Murthy, D. Garza, R.H. Scheller, T.L. Schwarz, Mutations in the exocyst component Sec5 disrupt neuronal membrane traffic, but neurotransmitter release persists, Neuron 37 (2003) 433-447.

[105] M. Shtrahman, C. Yeung, D.W. Nauen, G.Q. Bi, X.L. Wu, Probing vesicle dynamics in single hippocampal synapses, Biophys. J . 89 (2005) 3615-3627.

[106] D. Kamin, M.A. Lauterbach, V. Westphal, J. Keller, A. Schönle, S.W. Hell, S.O. Rizzoli, High- and low-mobility stages in the synaptic vesicle cycle, Biophys. J 99 (2010) 675-684.

[107] T.A. Ryan, L. Li, L.S. Chin, P. Greengard, S.J. Smith, Synaptic vesicle recycling in synapsin I knock-out mice, J. Cell Biol. 134 (1996) 1219-1227.

[108] L. Krabben, A. Fassio, V.K. Bhatia, A. Pechstein, F. Onofri, M. Fadda, M. Messa, Y. Rao, O. Shupliakov, D. Stamou, F. Benfenati, V. Haucke, Synapsin I senses membrane curvature by an amphipathic lipid packing sensor motif, J. Neurosci. 31 (2011) 18149-18154.

[109] F. Cesca, P. Baldelli, F. Valtorta, F. Benfenati, The synapsins: key actors of synapse function and plasticity, Prog. Neurobiol. 91 (2010) 313-348.

[110] M. Messa, S. Congia, E. Defranchi, F. Valtorta, A. Fassio, F. Onofri, F. Benfenati, 
Tyrosine phosphorylation of synapsin I by Src regulates synaptic-vesicle trafficking, J. Cell Sci. 123 (2010) 2256-2265.

[111] E. Neher, T. Sakaba, Multiple roles of calcium ions in the regulation of neurotransmitter release, Neuron 59 (2008) 861-872.

[112] X.S. Wu, S.H. Lee, J. Sheng, Z. Zhang, W.D. Zhao, D. Wang, Y. Jin, P. Charnay, J.M. Ervasti, L.G. Wu, Actin is crucial for all kinetically distinguishable forms of endocytosis at synapses, Neuron 92 (2016) 1020-1035.

[113] R. Fernandez-Busnadiego, S. Asano, A.M. Oprisoreanu, E. Sakata, M. Doengi, Z. Kochovski, M. Zürner, V. Stein, S. Schoch, W. Baumeister, V. Lucić, Cryoelectron tomography reveals a critical role of RIM1alpha in synaptic vesicle tethering, J. Cell Biol. 201 (2013) 725-740.

[114] Y. Han, N. Babai, P. Kaeser, T.C. Südhof, R. Schneggenburger, RIM1 and RIM2 redundantly determine $\mathrm{Ca}^{2+}$ channel density and readily releasable pool size at a large hindbrain synapse, J. Neurophysiol. 113 (2015) 255-263.

[115] G. Fischer von Mollard, T.C. Südhof, R. Jahn, A small GTP-binding protein dissociates from synaptic vesicles during exocytosis, Nature 349 (1991) 79-81.

[116] Y. Wang, M. Okamoto, F. Schmitz, K. Hofmann, T.C. Südhof, Rim is a putative Rab3 effector in regulating synaptic-vesicle fusion, Nature 388 (1997) 593-598.

[117] A.G. Leenders, F.H. Lopes da Silva, W.E. Ghijsen, M. Verhage, Rab3a is involved in transport of synaptic vesicles to the active zone in mouse brain nerve terminals, Mol. Biol. Cell 12 (2001) 3095-3102.

[118] N.J. Pavlos, R. Jahn, Distinct yet overlapping roles of Rab GTPases on synaptic vesicles, Small GTPases 2 (2011) 77-81.

[119] F. Ackermann, C.L. Waites, C.C. Garner, Presynaptic active zones in invertebrates and vertebrates, EMBO Rep. 16 (2015) 923-938.

[120] Y. Zhang, K. Chen, S.A. Sloan, M.L. Bennett, A.R. Scholze, S. O'Keeffe, H.P. Phatnani, P. Guarnieri, C. Caneda, N. Ruderisch, S. Deng, S.A. Liddelow, C. Zhang, R. Daneman, T. Maniatis, B.A. Barres, J.Q. Wu, An RNA-sequencing transcriptome and splicing database of glia, neurons, and vascular cells of the cerebral cortex, J. Neurosci. 34 (2014) 11929-11947.

[121] L. Sun, M.A. Bittner, R.W. Holz, Rim, a component of the presynaptic active zone and modulator of exocytosis, binds 14-3-3 through its N terminus, J. Biol. Chem. 278 (2003) 38301-38309.

[122] M. Iezzi, R. Regazzi, C.B. Wollheim, The Rab3-interacting molecule RIM is expressed in pancreatic beta-cells and is implicated in insulin exocytosis, FEBS Lett. 474 (2000) 66-70.

[123] H. Nomura, T. Ohtsuka, S. Tadokoro, M. Tanaka, N. Hirashima, Involvement of ELKS, an active zone protein, in exocytotic release from RBL-2H3 cells, Cell. Immunol. 258 (2009) 204-211.

[124] J. Neefjes, M.M.L. Jongsma, I. Berlin, Stop or go? Endosome positioning in the establishment of compartment architecture, dynamics, and function, Trends Cell Biol. 27 (2017) 580-594.

[125] G. Fischer von Mollard, B. Stahl, C. Walch-Solimena, K. Takei, L. Daniels, A. Khoklatchev, P. De Camilli, T.C. Südhof, R. Jahn, Localization of Rab5 to synaptic vesicles identifies endosomal intermediate in synaptic vesicle recycling pathway, Eur. J. Cell Biol. 65 (1994) 319-326.

[126] T. Wucherpfennig, M. Wilsch-Bräuninger, M. González-Gaitán, Role of Drosophila
Rab5 during endosomal trafficking at the synapse and evoked neurotransmitter release, J. Cell Biol. 161 (2003) 609-624.

[127] M.J. de Hoop, L.A. Huber, H. Stenmark, E. Williamson, M. Zerial, R.G. Parton, C.G. Dotti, The involvement of the small GTP-binding protein Rab5a in neuronal endocytosis, Neuron 13 (1994) 11-22.

[128] E.N. Star, A.J. Newton, V.N. Murthy, Real-time imaging of Rab3a and Rab5a reveals differential roles in presynaptic function, J. Physiol. 569 (2005) 103-117.

[129] H.M. McBride, V. Rybin, C. Murphy, A. Giner, R. Teasdale, M. Zerial, Oligomeric complexes link Rab5 effectors with NSF and drive membrane fusion via interactions between EEA1 and syntaxin 13, Cell 98 (1999) 377-386.

[130] A. Simonsen, J.M. Gaullier, A. D'Arrigo, H. Stenmark, The Rab5 effector EEA1 interacts directly with syntaxin-6, J. Biol. Chem. 274 (1999) 28857-28860.

[131] N.J. Pavlos, M. Grønborg, D. Riedel, J.J. Chua, J. Boyken, T.H. Kloepper, H. Urlaub, S.O. Rizzoli, R. Jahn, Quantitative analysis of synaptic vesicle Rabs uncovers distinct yet overlapping roles for Rab3a and Rab27b in $\mathrm{Ca}^{2+}$-triggered exocytosis, J. Neurosci. 30 (2010) 13441-13453.

[132] B. S;nnichsen, S. De Renzis, E. Nielsen, J. Rietdorf, M. Zerial, Distinct membrane domains on endosomes in the recycling pathway visualized by multicolor imaging of Rab4, Rab5, and Rab11, J. Cell Biol. 149 (2000) 901-914.

[133] P. Sheehan, M. Zhu, A. Beskow, C. Vollmer, C.L. Waites, Activity-dependent degradation of synaptic vesicle proteins requires Rab35 and the ESCRT pathway, J. Neurosci. 36 (2016) 8668-8686.

[134] P. Vanden Berghe, J. Klingauf, Synaptic vesicles in rat hippocampal boutons recycle to different pools in a use-dependent fashion, J. Physiol. 572 (2006) 707-720.

[135] V. Marra, J.J. Burden, J.R. Thorpe, I.T. Smith, S.L. Smith, M. Häusser, T. Branco, K. Staras, A preferentially segregated recycling vesicle pool of limited size supports neurotransmission in native central synapses, Neuron 76 (2012) 579-589.

[136] C. Salaün, G.W. Gould, L.H. Chamberlain, The SNARE proteins SNAP-25 and SNAP-23 display different affinities for lipid rafts in PC12 cells. Regulation by distinct cysteine-rich domains, J. Biol. Chem. 280 (2005) 1236-1240.

[137] C. Salaün, D.J. James, L.H. Chamberlain, Lipid rafts and the regulation of exocytosis, Traffic 5 (2004) 255-264.

[138] C. Risinger, M.K. Bennett, Differential phosphorylation of syntaxin and synaptosome-associated protein of $25 \mathrm{kDa}$ (SNAP-25) isoforms, J. Neurochem. 72 (1999) 614-624.

[139] H.B. Nielander, F. Onofri, F. Valtorta, G. Schiavo, C. Montecucco, P. Greengard, F. Benfenati, Phosphorylation of VAMP/synaptobrevin in synaptic vesicles by endogenous protein kinases, J. Neurochem. 65 (1995) 1712-1720.

[140] C. Rickman, R.R. Duncan, Munc18/Syntaxin interaction kinetics control secretory vesicle dynamics, J. Biol. Chem. 285 (2010) 3965-3972.

[141] N. Holderith, A. Lorincz, G. Katona, B. Rózsa, A. Kulik, M. Watanabe, Z. Nusser, Release probability of hippocampal glutamatergic terminals scales with the size of the active zone, Nat. Neurosci. 15 (2012) 988-997.

[142] D. Fasshauer, Structural insights into the SNARE mechanism, Biochim. Biophys. Acta 1641 (2003) 87-97. 